\title{
Médiévales
}

Langues, Textes, Histoire

78 | printemps 2020

Moyen Âge en séries

\section{Pierre Dubois, De la reconquête de la Terre sainte. De l'abrègement des guerres et procès du royaume des}

\section{Francs}

éd. et trad. Marianne Saghy, Alexis Leonas, Pierre-Anne Forcadet, Paris, Les Belles Lettres («Bibliothèque scolastique », 14), 2019, LXVIII-540 p.

\section{Loïc Chollet}

\section{OpenEdition}

\section{Journals}

Édition électronique

URL : https://journals.openedition.org/medievales/10966

DOI : 10.4000/medievales. 10966

ISSN : 1777-5892

\section{Éditeur}

Presses universitaires de Vincennes

Édition imprimée

Date de publication : 20 août 2020

Pagination : 221-223

ISBN : 978-2-37924-093-5

ISSN : 0751-2708

\section{Référence électronique}

Loïc Chollet, «Pierre Dubois, De la reconquête de la Terre sainte. De l'abrègement des querres et procès du royaume des Francs », Médiévales [En ligne], 78 | printemps 2020, mis en ligne le 09 novembre 2020 consulté le 23 avril 2022. URL : http://journals.openedition.org/medievales/10966 ; DOI : https:// doi.org/10.4000/medievales. 10966

Ce document a été généré automatiquement le 23 avril 2022

Tous droits réservés 


\section{Pierre Dubois, De la reconquête de la Terre sainte. De l'abrègement des guerres et procès du royaume des} Francs

éd. et trad. Marianne Saghy, Alexis Leonas, Pierre-Anne Forcadet, Paris, Les Belles Lettres («Bibliothèque scolastique », 14), 2019, LXVIII-540 p.

Loïc Chollet

\section{RÉFÉRENCE}

Pierre Dubois, De la reconquête de la Terre sainte. De l'abrègement des guerres et procès du royaume des Francs, éd. et trad. Marianne Saghy, Alexis Leonas, Pierre-Anne Forcadet, Paris, Les Belles Lettres (« Bibliothèque scolastique », 14), 2019, LXVIII-540 p.

1 Il est certaines œuvres de la littérature médiévale dont on ne cesse de louer la modernité. Celles de Pierre Dubois, juriste normand ayant vécu à la charnière des XIII ${ }^{\mathrm{e}}$ et XIV ${ }^{e}$ siècles, sont assurément de celles-ci. Son écrit le plus connu, De la reconquête de la Terre sainte, propose une réforme radicale de la chrétienté latine, avec en toile de fond la récupération de la Terre sainte dont les Occidentaux ont été expulsés quelques années auparavant. Bien que citée tour à tour par les partisans de la laïcité ou de l'unité européenne, l'œuvre de Dubois ne bénéficiait pas d'une traduction satisfaisante en français. C'est chose faite, grâce à une petite équipe de chercheurs réunis autour de Marianne Sághy (Central European University, Budapest), malheureusement décédée juste avant la parution du livre.

2 Ce volume ne propose en réalité pas une, mais deux œuvres de Pierre Dubois : d'une part, le De la reconquête, d'après le texte établi par Charles-Victor Langlois, corrigé et traduit par Marianne Sághy et Alexis Léonas (Université Káspár Károli, Budapest) et, d'autre part, le De l'abrègement des guerres et procès du royaume des Francs, édité et traduit 
par Pierre-Anne Forcadet (Université d'Orléans). Pour ces deux essais, l'original latin est accompagné de la traduction française en regard, ce qui facilite la lecture, mais aussi le travail de l'historien. Car ce livre est amené à servir de source à de nombreux médiévistes, les sujets énumérés par Dubois pouvant alimenter des réflexions sur nombre d'aspects de la société médiévale européenne. Dans cette optique peut-être, les éditeurs ont pris le parti de faciliter au possible l'accès à leur matière. L'introduction générale, succincte, mais précise, permet de se faire une idée de l'auteur, des thématiques qu'il aborde et de sa réception parmi les historiens européens. Chacun des essais est précédé d'une introduction thématique présentant les manuscrits et les principes d'édition, sans oublier un résumé de l'œuvre. Des sous-titres ont été ajoutés aux différentes parties du plus long De la reconquête, un découpage du texte facilitant la lecture.

Le premier essai proposé n'est toutefois pas le plus ancien. De la reconquête a été composé entre 1305 et 1307, dans un contexte bien particulier. En 1291 est tombé SaintJean d'Acre, la dernière place forte de la Terre sainte aux mains des chrétiens. C'en est fini des États latins d'Outremer. Une vaste réflexion s'amorce sur les causes de ce qui est perçu comme un échec, et sur les moyens d'y remédier. Papes et rois consultent les grands maitres du Temple et de l'Hôpital, reçoivent des traités aussi variés que ceux du Catalan Raymond Lulle, du Vénitien Marino Sanudo Torsello ou du prince arménien Héthoum (Hayton) de Korykos. Bien qu'il ne soit pas lui-même un connaisseur de la Méditerranée orientale, Pierre Dubois semble avoir imaginé que son avis pouvait intéresser les décideurs d'alors. L'essentiel de ses réflexions, toutefois, ne portent pas sur l'Orient, mais sur l'Europe, et moins sur des questions de stratégie que de réorganisation politique et religieuse. La matrice de ses idées se trouve déjà dans son premier traité connu, le De l'abrègement des guerres et procès, daté de 1300.

4 Le cœur de la pensée développée par l'auteur est la réforme de la chrétienté, qui devrait être effectuée sous l'égide du roi de France au détriment de la puissance ecclésiastique. Considérant que l'administration de territoires et de biens fonciers représente une charge pour les prélats, Pierre Dubois propose que ceux-ci soient « libérés» de ces soucis temporels. Une fois les biens de l'Église administrés par des laïcs, les ecclésiastiques pourraient se consacrer à plein temps au salut des âmes et travailleraient efficacement à propager la paix par l'organisation de conciles. Dubois voit ceux-ci comme des forums internationaux, où l'on inviterait tous les dignitaires chrétiens, y compris les usurpateurs supposés, pour établir la paix entre les États et à l'intérieur de ceux-ci. Les réfractaires seraient déclarés rebelles puis soumis à la guerre et aux blocages économiques.

5 Deux ajouts de taille distinguent De la reconquête de son prédécesseur : l'organisation d'une croisade afin de reprendre pied en Terre sainte, et la refonte de l'éducation. Dans le premier cas, les critiques envers les Templiers et les autres ordres militaires renforcent son projet de séculariser les biens de l'Église. Dans le second cas, la nécessité d'obtenir rapidement de bons spécialistes amène Dubois à proposer des études plus courtes, alliant théorie et pratique, ouvertes aux femmes et mettant l'accent sur l'apprentissage des langues parlées en Orient. D'autres idées à nos yeux remarquablement modernes apparaissent çà et là, comme lorsque l'auteur préconise le mariage chez les religieux, afin de légaliser une pratique cachée, mais courante... des idées provocatrices, ce dont Dubois est parfaitement conscient. Aussi n'a-t-il de cesse de recommander la discrétion à ses destinataires. 
6 L'introduction permet de faire plus ample connaissance avec l'auteur de ces audacieuses propositions, même si l'on ne sait pas grand-chose sur la vie de Pierre Dubois. Juriste cultivé (il connaissait en autres Roger Bacon, Thomas d'Aquin, Boèce et Ovide), l'homme gravitait autour des cercles du pouvoir sous le règne de Philippe IV le Bel. Plusieurs conseillers du roi comptaient parmi ses amis, sans qu'il ne semble avoir bénéficié de la protection d'un Guillaume de Nogaret. Il semble plutôt que Dubois ait essayé de séduire le petit groupe de légistes dont Philippe le Bel s'entourait, ce qui explique son parti pris « royal » dans la querelle opposant la couronne de France à la Papauté. Surtout, l'héritage de la pensée scolastique et le désir inhérent de réformer la chrétienté se reflètent dans les aspects considérés comme les plus audacieux de l'œuvre de Dubois.

7 Une fois contextualisés, les écrits de ce juriste ressemblent moins à d'exceptionnels appels à l'innovation nés dans la nuit d'un sombre Moyen Âge qu'à des éléments révélant une toile plus large, celle d'une "république des lettres » où philosophes, juristes, diplomates et poètes réfléchissent aux moyens d'améliorer leur(s) société(s). Comme chez les auteurs de son temps, c'est bien l'idéal chrétien qui est au cœur du projet de Dubois : même son anticléricalisme, l'un des aspects considérés comme les plus «modernes » de son œuvre, ne vise qu'à rendre à l'Église sa mission originelle, à savoir le salut des âmes. À cela s'ajoute un "patriotisme» exacerbé, là encore un phénomène assez courant chez les hommes de lettres de la fin du Moyen Âge, et pas uniquement en France. Dans le cas qui nous occupe, le projet de mise sous tutelle de la papauté s'accompagne d'une proposition visant à faire du Saint-Empire une monarchie héréditaire, placée sous le sceptre d'un frère du roi de France. Car les Français seraient amenés à dominer le monde, eux qui sont les plus rationnels des hommes.

La sécularisation des biens du clergé, la réorganisation du monde politique et la pacification de la chrétienté visent donc à concrétiser cette idée chère aux penseurs médiévaux : la reformatio, le retour à une société chrétienne idéale. Pour les hommes de lettres français, la chrétienté ne peut être réformée que sous la tutelle du roi de France et en cela Dubois ne fait pas exception : il écrivait dans le contexte du conflit entre Philippe le Bel et les papes Boniface VIII et Clément V, conflit ayant amené la «pontificalisation » du monarque français, selon la belle formule de Julien Théry. À cet éloge de la France et de son roi fait écho un regard critique, voire condescendant, sur les autres nations européennes. Les turbulentes villes italiennes devraient être remises au pas, le roi de Castille - illégitime - devrait être renversé, et l'anarchie endémique dans le Saint-Empire serait réglée si l'on y appliquait les recettes ayant fait le succès de la monarchie française. Quant à Constantinople, l'empereur Paléologue est un usurpateur et la ville impériale appartient de droit à Charles de Valois, héritier de l'Empire latin par mariage.

9 Les projets a priori les plus novateurs sont, quant à eux, mis au service de la progression ou de la défense de la foi. Les filles éduquées fourniront des chirurgiennes vouées à soigner les combattants de la Terre sainte; certaines d'entre elles seront mariées aux chefs religieux et politiques orthodoxes et musulmans. Dans l'esprit de Dubois, l'expansion du catholicisme passe par l'acculturation. C'est dans la même logique que l'auteur défend l'apprentissage des langues orientales. Les Français peuvent bien chasser les Paléologues de Constantinople, mais les armes ne leur suffiront pas à se faire accepter par les Grecs. Les conquérants auront besoin d'interprètes formés en 
France pour communiquer avec leurs nouveaux sujets, d'autant plus que - Dubois le rappelle - ceux-ci considèrent les Occidentaux comme des barbares.

10 C'est une image bien ambiguë que nous renvoient les deux essais présentés dans ce volume. À l'instar d'autres auteurs médiévaux, Pierre Dubois illustre un courant de la pensée politique européenne fermement ancré dans un christianisme militant, tout en innovant par les moyens envisagés pour atteindre ses buts. Des parallèles peuvent être faits avec d'autres concepteurs de l'Europe unie, tels que Philippe de Mézières (m. 1405) ou le roi de Bohême Georges de Podiebrady (m.1471). Comme chez Dubois, la paix en Europe doit servir de prélude à la guerre contre les Mamelouks et les Turcs, qui tiennent la Terre sainte et menacent les royaumes catholiques de l'Europe centreorientale. Quant à l'apprentissage des langues étrangères, il appartient au registre de la mission: au XIII siècle déjà, le légat pontifical Guillaume de Modène (m.1251) recommandait aux missionnaires dépêchés auprès des païens de la Baltique d'apprendre les idiomes locaux. La pensée de Pierre Dubois mériterait d'être confrontée avec celle d'autres auteurs de l'Europe médiévale, mais là n'est pas le propos de cet ouvrage. Il s'agit plutôt d'une piste à suivre, parmi d'autres. Ce qu'ont voulu faire Marianne Sághy, Alexis Léonas et Pierre-Anne Forcadet, c'est mettre à la disposition des chercheurs deux textes intrigants, amenés à nourrir les discussions sur cette période charnière qu'est le bas Moyen Âge. Un travail magistralement réussi.

\section{AUTEURS}

\section{LOÏC CHOLLET}

Université de Neuchâtel 